\section{Novas TeCNOLOGIAS EDUCACIONAIS: \\ UMA CULTURA EMERGENTE NA FORMAÇÃO DOCENTE*}

Maria Augusta Bernardo Marques de Mendonça**

\section{Introdução}

Nas últimas décadas, as demandas emergentes e as transformações constantes, impulsionadas pelas tecnologias de informação e comunicação TIC, ampliaram as complexidades sociais determinando mudanças na sociedade globalizada, na forma de ensinar e, conseqüentemente, na formação docente. Assim sendo, a formação continuada foi instituída legalmente na educação brasileira pela nova LDB 9394/96, originando no ano seguinte a portaria MEC $\mathrm{n}^{\mathrm{o}} 522$ para o desenvolvimento do PROINFO - Programa Nacional de Informática na Educação.

O programa, por meio de uma coordenação estadual, vem promovendo ações para introdução das novas tecnologias objetivando melhorar a qualidade do ensino-aprendizagem, possibilitar a criação de uma nova ecologia cultural e propiciar uma educação voltada para o desenvolvimento científico e tecnológico (BRASIL, 2003).

Segundo Moraes (1997), desde 1971 as universidades brasileiras promovem ações isoladas com auxílio financeiro de fundações, entretanto, somente após 1996 com o apoio do Banco Mundial e com a nova LDB 9394 efetiva-se a formação continuada em serviço. Nos termos legais da LDB temos que os sistemas de ensino promoverão a valorização dos profissionais da educação, assegurando-lhes, inclusive nos termos dos estatutos e dos planos de carreira do magistério e pelo inciso II - aperfeiçoamento profissional continuado, inclusive com licenciamento remunerado para esse fim (BRASIL, 1996, p.31).

No Estado de São Paulo, coordenando o PROINFO encontramos a

* Trabalho de pesquisa de Mestrado, defesa em novembro 2003 - UNESP/Araraquara, apresentado no VI Encontro de Pesquisa em Educação da Região Sudeste, Rio de Janeiro - maio 2004 e XII ENDIPE (Encontro Nacional de Didática e Prática de Ensino), Curitiba - agosto 2004

** Mestre em Educação Escolar e graduada em Matemática. Professora de Informática Educacional no Curso Normal Superior do Departamento de Ciências Humanas e Sociais da UNIARA.
SEESP - Secretaria de Estado da Educação de São Paulo e GIP/FDE - Gerência de Informática Pedagógica da Fundação para o Desenvolvimento da Educação, orientando trabalhos realizados pelos NRTEs - Núcleos Regionais de Tecnologias Educacionais, pólos em que os professores multiplicadores realizam capacitações sobre as novas tecnologias educacionais para docentes da rede pública.

Teoricamente, as diretrizes legais constituem um conjunto de ações que atenderiam a lógica do sucesso para um ensino inovador com bases na cultura emergente, oferecendo condições de transformações nas práticas pedagógicas. Porém, os resultados das capacitações vêm indicando insucessos, deixando-se apenas alguns fragmentos de conhecimentos e sem vínculos com as ações.

Algumas das escolas públicas participantes do PROINFO vêm apresentando as seguintes situações: salas de informática fechadas ou abertas, contudo, sem pessoas credenciadas para administrá-las; alguns professores sendo capacitados pelos NRTEs locais, mas com dificuldades de utilização da SAI-Sala Ambiente de Informática e de multiplicar os conhecimentos recebidos; coordenadores pedagógicos desvinculados das novas tecnologias, ou mesmo, sem condições de administrar projetos pedagógicos inovadores; diretores resistentes à tecnologia, ou que, mantém um certo distanciamento; utilização da Internet sem vínculo com o conteúdo da disciplina, dando abertura para que alunos visitem sites impróprios, sem qualquer relação com temas educacionais e outras situações menos relevantes.

$\mathrm{O}$ contexto descrito vem causando inquietações e questionamentos associados à necessidade de investigar e, sobretudo, de compreender quais são os fatores internos ou externos que causam dificuldades na incorporação das novas tecnologias nas escolas públicas, considerando-se a sua importância para a qualificação do ensino.

Nessa perspectiva, o trabalho buscou avaliar os seguintes aspectos das questões norteadoras: formação inicial como um fator estimulante; local de formação continuada como fator determinante para utilização; os obstáculos da nova ecologia educacional; as dificuldades pessoais dos docentes; os fatores que respondem como estímulo e as perspectivas dos professores para utilização.

Assim, a pesquisa teve como foco principal a incorporação da cultura emergente na formação docente, ou seja, compreender como essas novas tecnologias educacionais vêm sendo tratadas pelas formações continuadas e incluídas nas práticas pedagógicas.

\section{Formação docente: estudos e reflexões}

Papert (1994) sensibiliza os representantes da educação, mostrando que o ensino está distante da realidade ou da sociedade da informação. Sendo assim, existe a necessidade de rever tanto o papel da educação na sociedade quanto do educador em relação às novas tecnologias. 
Nesse sentido, Moran (2000) promove discussões convergidas para a revisão no papel do professor nos dias atuais e afirma que a "sociedade da informação" ao estimular o movimento constante de inovações, passa a exigir atualização dos profissionais da educação em serviço.

Nessa perspectiva, Kenski (2001) traz a proposta desafiadora para a formação docente, que consiste em saber lidar com situações antagônicas numa sociedade composta por realidades conflitantes. Assim, esse desafio nos conduz a refletir sobre as práticas pedagógicas e suas necessidades, visando novas competências e novos paradigmas formativos.

Segundo Perrenoud (2000) as competências emergentes devem orientar as formações iniciais e contínuas, determinando o desenvolvimento das mais profundas racionalidades, e uma delas se situa na utilização das novas tecnologias educacionais.

Na perspectiva de enfrentamento das dificuldades, Marin (1996) afirma que o estímulo do professor está dentro de si mesmo. Diante disso, podemos supor que dificuldades e problemas existentes nas formações iniciais ou contínuas devem caminhar na direção da compreensão e da união.

Numa perspectiva reflexiva sobre a formação docente, Cavaco (1991) discute a importância da reflexão partilhada para permitir questionamento das dificuldades na profissão do professor e de outros aspectos presentes nas escolas Sendo assim, a reflexão definida por Zeichner (1993) considera três aspectos: o primeiro, o educador age buscando os conhecimentos adquiridos e os enquadra no contexto dos alunos; num segundo aspecto, considera-se sua convivência com todas as classes sociais e políticas e, num terceiro aspecto, demonstra sua reflexão por meio da prática social. Gómez (1992) afirma que pela reflexãona-ação o educador, numa situação de pressão da vida escolar, poderá buscar conhecimentos adquiridos ativando recursos intelectuais (conceitos, teorias, crenças, dados, procedimentos, técnicas) ao elaborar um diagnóstico rápido da situação em busca por novas estratégias de intervenção.

Numa análise crítica ao modelo neoliberal de educação, Libâneo (2001) desafia os educadores críticos a repensar nos objetivos e nos processos pedagógico-didáticos em conexão com as relações existentes entre educação e economia, educação e sociedade técnica-científica-informacional, para além dos discursos contra o domínio do mercado e da exclusão social.

\section{Procedimentos metodológicos}

$\mathrm{O}$ desafio investigativo foi trilhado numa abordagem avaliativa e qualitativa. Neste sentido, Lüdke e André (1986, p.11-13) oferecem orientações para a pesquisa qualitativa fundamentadas em cinco características básicas: a primeira, pelo ambiente natural como fonte direta de dados e o pesquisador como seu principal instrumento; a segunda, pelos dados coletados predominantemente descritos; a terceira, pela preocupação com o processo maior do que com o produto; a quarta, em capturar os significados e as perspectivas dos participantes do projeto de ação e a quinta, a análise dos dados tendendo para um processo indutivo.

Com o objetivo da aproximação de possíveis respostas para as questões norteadoras, foram seguidas as sugestões propostas por Lüdke e André (1986), utilizando-se os diferentes instrumentos em diferentes momentos: diagnóstico inicial (questionário), ficha de auto-avaliação (documental) e fichas de observação das ações e reações em situações-problema.

\section{Pesquisa num projeto de ação}

O projeto de ação, intitulado Projeto do Ensino de Múltiplas Mídias, realizou-se numa escola pública do ensino fundamental de Araraquara/SP, no período de outubro de 2002 a maio de 2003. A metodologia aplicada em cada módulo do projeto de ação foi estabelecida a partir do ciclo descriçãoexecução-reflexão-depuração, tendo como base sugestões de Almeida (2000) e Valente (1999), buscando facilitar organização das etapas e a compreensão dos dados obtidos. A descrição aconteceu durante o planejamento da pesquisa e a organização do projeto de ação. A execução ocorreu na fase do processamento das informações por meio da realização das ações planejadas. A reflexão sucedeu na fase da avaliação e da comparação dos resultados obtidos com os esperados, realizando assim, o estudo das possíveis estratégias de modificação. A depuração aconteceu durante a aplicação das novas estratégias, reiniciando o ciclo para reavaliar os novos resultados.

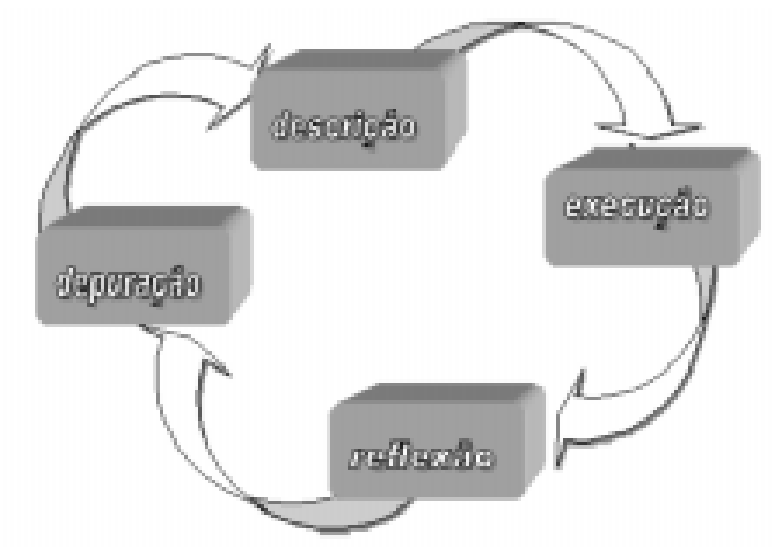

Assim, o projeto de ação foi estruturado em três módulos e subdivido em etapas da seguinte forma: 
Tabela das ações realizadas nos três módulos

\begin{tabular}{|c|c|c|c|c|c|}
\hline Mód & Sajeitos & Eneontros & Horas & Açốes & Periode(meses) \\
\hline $\mathbf{I}$ & 14 & 17 & 17 & Capacitacão na SAI da escola & $16 / 10$ a $11 / 12 / 2002$ \\
\hline II & 9 & 27 & $22 \mathrm{~h} 30$ & Aplicaçầo dos planos de aulas & $12 / 03$ a $11 / 04 / 2003$ \\
\hline III & 5 & 59 & $49 \mathrm{~b} 10$ & Aplicaçà̀ em outros projetos & $05 / 05$ a $30005 / 2003$ \\
\hline Total & - & 103 & 88bato & 3 & 6 \\
\hline
\end{tabular}

Fontes: Fichas de observação dos sujeitos nos módulos I, II e III

A participação dos sujeitos da pesquisa contou com a colaboração da diretora recém-efetivada, abrindo espaço na escola para a realização da pesquisa e auxiliando no estímulo dos professores. No período de pesquisa aconteceram 103 encontros, entre 16 de outubro de 2002 e 30 de maio de 2003 , perfazendo um total de $88 \mathrm{~h} 40$

\section{MÓDULO I - Capacitando para as Novas Tecnologias}

Objetivos da pesquisa: diagnosticar, observar e avaliar os sujeitos;

Objetivos do projeto de ação (Etapas):

1. Introdução: Apresentação das diretrizes do projeto aos participantes. Aplicação do questionário para diagnosticar a formação inicial, levantando os conhecimentos sobre informática, a prática pedagógica e as opiniões sobre as mudanças educacionais;

2. Exploração dos recursos existentes na SAI: Micros, TV/Vídeo, TV/Micro, Impressora, Scanner, Internet, Aplicativos e principalmente softwares educacionais. Preenchimento da ficha de auto-avaliação, solicitando os caminhos percorridos e as dificuldades encontradas;

3. Seleção de assuntos e dos recursos: Para elaboração de um plano de aula, prevendo uma que possivelmente seria dada no $1^{\circ}$ bimestre de 2003 .

4. Discussão e reflexão sobre sua prática: $\mathrm{Na}$ busca por formas de enriquecê-la, utilizando-se novos recursos tecnológicos educacionais

5. Elaboracão de um plano de aula: Preenchimento dos campos do plano, explorando os possíveis recursos apresentados e existentes na escola (sala de aula, biblioteca e outros).

6. Digitação do plano de aula: utilizando-se o aplicativo Word no sentido de aprender e gerar cópias para setores de interesse como: direção, coordenação da escola, professores (sujeitos) e documentação da pesquisa.

Neste módulo, os encontros foram de uma hora em HTPC's, contando com a participação de 14 sujeitos (10 efetivos e 4 ACT's), apenas um do sexo masculino. Esse grupo apresentava as seguintes características: média de idade de 46 anos, média formação de 18 anos, 7 pedagogas e atualizações em outras formações.
Gráfico. Amostragem dos sujeitos participantes da pesquisa

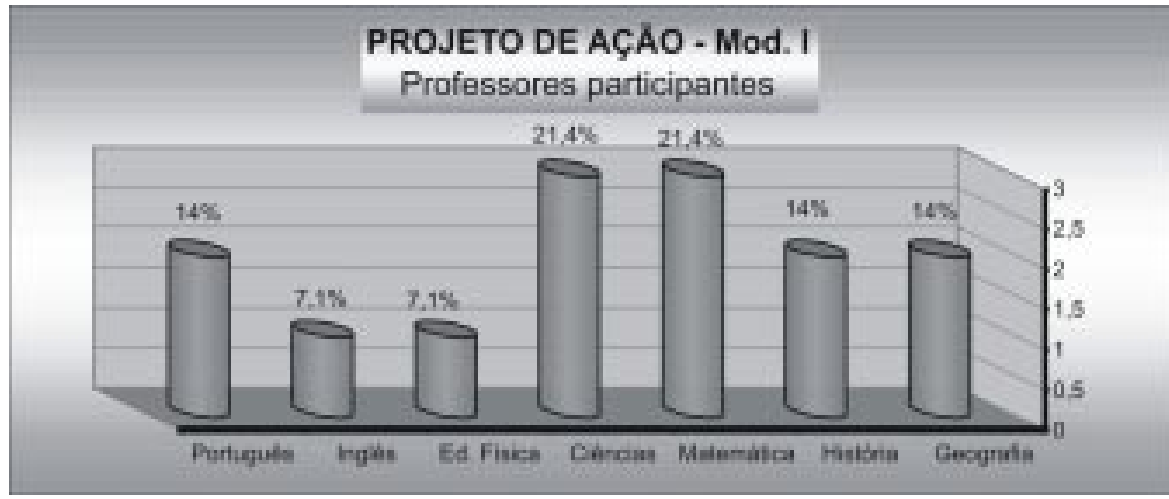

Fonte: Tabela baseada nas listas de presenças dos sujeitos no módulo I

\section{MÓDULO II - Aplicando projetos de múltiplas mídias}

Objetivos da pesquisa: observar e avaliar os sujeitos promovendo situações-problema.

Objetivos do projeto de ação: (Etapas)

1. Preparação do ambiente: Elaboração dos horários da SAI de acordo com as necessidades dos docentes, seleção e orientação alunos-monitor no auxílio técnico.

2. Aplicação dos planos de aula com os alunos: Aconteceram em três encontros de duas horas-aulas. No primeiro, os alunos exploraram os materiais disponíveis para aula. No segundo, os alunos executaram atividades propostas pelos professores, utilizando os recursos explorados. No terceiro, os alunos elaboraram trabalhos avaliativos sobre o assunto.

Neste módulo, as atribuições de aulas determinaram novos destinos para alguns docentes: três ACT's não conseguiram aulas nessa unidade escolar, um professor efetivo se aposentou e uma professora efetiva foi a uma direção escolar na cidade de São Paulo, entretanto, todas as professoras participantes do módulo levaram seus alunos na SAI e realizaram seus planos de aulas.

\section{MÓDULO III - Avaliando e reavaliando informações}

Objetivos da pesquisa: avaliar as informações do módulo II, estudar as tendências da continuidade espontânea, observando as reações dos sujeitos no convite para compor um horário da SAI e reavaliar as informações obtidas nos módulos anteriores.

Sendo assim, as etapas foram:

1. Elaboração do horário da SAI: colaborando com a escola e estimulando a continuidade de aplicação de outros projetos da escola; 
2. Análise dos resultados finais: Comparação dos resultados obtidos com os atuais.

Neste módulo, foram consideradas as ações realizadas por quatro professoras na SAI: duas professoras de Português, uma Geografia e uma de História.

\section{Resultados da pesquisa}

Para compor os resultados procuramos identificar dentre os fatores internos e externos, os aspectos positivos e negativos que vêm causando dificuldades na inclusão das novas tecnologias nessa escola pública.

\section{Fatores externos}

\section{Formação continuada oferecida pelo NRTE local}

Na visão dos sujeitos, as capacitações oferecidas pelo núcleo de tecnologia são necessárias, importantes para o relacionamento com os alunos e para o crescimento pessoal, entretanto, apresentam queixas a respeito da organização e da forma que recebem as informações. Os aspectos positivos foram: a aquisição de novos conhecimentos para melhorar a relação com seus alunos, as trocas de experiências entre os colegas de outras escolas, o computador como motivador do ensino-aprendizagem, complemento do trabalho em sala de aula e o recurso atraente para pesquisa. Enquanto que, os aspectos negativos apontados foram: o tempo de capacitação em relação à quantidade de informações dadas, as capacitações não-seqüenciais (ausência de pré-requisitos), os cursos oferecidos a poucos que não conseguem repassar seus conhecimentos, a ausência de assistências nas escolas, a distância entre a capacitação e a aplicação na escola das informações recebidas que vem causando esquecimento dos detalhes e as diferenças encontradas entre os micros da escola.

Os depoimentos nos indicaram "insegurança" pelo local da capacitação, devido alguns aspectos significativos, tais como: a quantidade de informações recebidas e distância de aplicação na escola; as diferenças encontradas entre as configurações dos micros de capacitação e da aplicação; a adaptação com os recursos existentes na própria escola, considerando-se a existência de realidades diferentes.

\section{Mudanças educacionais}

Na visão dos sujeitos, as mudanças são necessárias e urgentes, porém as queixas denotam algumas insatisfações. Os aspectos positivos indicaram aceitação das mudanças, mesmo diante dos receios. Por outro lado, os aspectos negativos demonstraram insastifações pelo sistema educacional copiado de outros países; pelas ordens verticais sem relação com suas realidades, pelas mudanças radicais desprovidas de orientações e sem solução no ensinoaprendizagem e pela progressão continuada promovendo desinteresses, dificultando a relação professor-aluno e denegrindo a profissão docente.

\section{Fatores internos}

\section{Sujeitos e suas características pessoais}

As características observadas auxiliam a analisar a profissão de professor na atualidade, sendo que existem poucos professores abaixo de 40 anos. Entretanto, independente da idade dos sujeitos, ocorreram adaptações pelas novas tecnologias educacionais. Os aspectos positivos declarados foram: a longa experiência na profissão, gostam do que fazem, nove sujeitos receberam formação continuada em novas tecnologias no período de 1999 a 2002 e a existência de duas professoras multiplicadoras na escola. Entretanto, os aspectos negativos foram: poucos professores jovens na escola, alguns na função de eventuais, poucos sujeitos receberam capacitações em novas tecnologias, ausência de registros constando multiplicações locais e o excesso de movimentações dos sujeitos entre escolas.

Com base nessas informações, foi possível perceber que os sujeitos, independente de suas formações e interesses pessoais, tendem a reagir conforme as circunstâncias apresentadas, buscando superar as inseguranças quando recebem a motivação adequada.

\section{Aplicações na prática pedagógica}

Os sujeitos que haviam realizado tentativas de utilização da SAI, declararam em unanimidade suas inseguranças vindas por: conhecimento insuficiente; não familiarização com os micros devido a diferentes configurações entre as máquinas de capacitação e de aplicação; tempo para preparação de aulas com esses novos recursos e ausências de pessoas técnicas na própria escola para auxiliar nas situações mencionadas. Assim, os aspectos positivos mencionados foram: a coragem de tentar a utilização da SAI, independente das dificuldades encontradas e o apoio dos alunos que sabem lidar com os computadores. Contudo, os aspectos negativos relatados foram inseguranças causadas: pela não familiarização com os micros devidos os problemas físicos que ocorrem e pela falta de tempo de planejar aulas ou projetos utilizando-se as novas tecnologias. Nesse sentido, acreditamos que um coordenador de informática poderia ser o profissional indicado para dar assistência local nas situações das inseguranças mencionadas. 


\section{Ambientação escolar}

Esses aspectos nos revelaram que a escola possui ambientação propícia a inclusão digital, entretanto, não existe pessoal na escola especializado para essa finalidade. Os aspectos positivos mencionados foram: a ampla instalação da escola e os diferentes ambientes educacionais propícios para os novos conhecimentos. Todavia, os aspectos negativos foram à ausência de pessoas técnicas de informática para: organizar o funcionamento da SAI, orientar monitores de informática e capacitar professores no próprio local de serviço.

\section{Sala Ambiente de Informática - SAI}

A SAI possui recursos tecnológicos complexos e diferenciados de um giz e lousa, contudo não possui pessoal especializado para atender os objetivos propostos para o PROINFO. Sendo assim, podemos considerar como aspecto positivo, que a SAI possui todos os recursos tecnológicos oferecidos pelo PROINFO. No entanto, os aspectos negativos observados foram: a quantidade insuficiente de CDs educativos para atender todas as máquinas, ausência de padronização dos softwares educativos e a inexistência de um coordenador de informática

\section{Softwares Educacionais e outros recursos da SAI}

$\mathrm{Na}$ visão geral da maioria dos sujeitos, os softwares educacionais são interessantes como material pedagógico, entretanto, apresentam muitas dificuldades na utilização. Assim, o aspecto positivo observado foi a afinidade dos sujeitos com softwares educativos. Enquanto que, os aspectos negativos foram: o tempo insuficiente para explorar os softwares educativos, as formas diferentes de manipulações e instalações entre os programas, a adaptação dos professores com a linguagem técnica, a incompatibilidade entre os recursos da SAI, travamentos durante as explorações, a quantidade insuficiente em relação à quantidade de micros e a ausência de padrões entre os softwares educativos.

Diante das dificuldades apresentadas foi possível compreender a ausência de curiosidade dos sujeitos pelos softwares educativos, antes do projeto de ação. Assim, eliminando-se as possibilidades de rejeições ou resistências pelos sujeitos, subsistem as dificuldades promovendo desinteresses.

\section{Perspectivas dos docentes}

No decorrer do projeto de ação, os professores apresentaram qualidades que podem auxiliar na superação das dificuldades. Logo, os aspectos positivos declarados foram: a curiosidade pelos recursos tecnológicos da SAI, o interesse pela formação continuada, a consciência das necessidades de seus alunos pelas novas tecnologias, a procura por outras formações, a maioria deles com computador em casa e o cumprimento de todas as etapas do projeto de ação. Entretanto, os aspectos negativos observados foram: o distanciamento dos softwares educativos, o excesso de movimentações entre escolas promovidas pelas atribuições de aulas e a ausência da valorização dos certificados das formações continuadas devido a inexistência de uma pontuação que possa contabilizar para as atribuições de aulas.

Com base nas informações obtidas foi possível perceber que as perspectivas dos professores oscilam entre os aspectos positivos e negativos. Apesar de considerarem as novas tecnologias interessantes, os obstáculos sobressaem ao desejo da prática.

\section{Considerações finais}

Os sujeitos participantes do módulo inicial souberam reconhecer o benefício das capacitações oferecidas nos núcleos regionais, extraindo aspectos positivos que possibilitaram entender e praticar os usos da informática nas suas atividades docentes. No entanto, apontaram vários aspectos negativos que merecem ser discutidos, entre os quais a falta de uma sistemática de capacitação, dando a entender que ocorrem de forma aleatória; incompatibilidade entre as configurações dos micros do núcleo e os da sala de informática de suas escolas, o que, evidentemente, dificultam a transferência dos conhecimentos para os alunos da unidade escolar; ausência da assistência de um pessoal especializado na própria escola, inviabilizando as iniciativas para o uso com os alunos; o acervo existente nas escolas sem vínculo pedagógico; ausência de continuidade das capacitações pelo professor-multiplicador na escola origem; a não valorização dos certificados das formações continuada, gerando desmotivações e, outros aspectos que merecem ser exibidos e discutidos em outras iniciativas deste teor.

Quanto aos fatores internos, na opinião dos docentes sujeitos, há aspectos positivos que colaboram nas capacitações, assim como há inúmeros outros que se traduzem em empecilhos para a realização da formação continuada. Dos primeiros, registramos o fato de atribuírem importância à capacitação feita nos moldes desse projeto de ação, sem excluir a necessidade das capacitações externas, mas vêem maior compromisso e mais estímulo quando a própria unidade escolar se empenha em iniciativas deste porte. Ainda, como fator positivo existiu o fato de serem acompanhados ao aplicar os seus conhecimentos com os alunos, sendo observados e estimulados para isso. Destacamos um outro aspecto positivo que se refere ao poder de iniciativa do próprio docente, mesmo que tenha dificuldades em manipular o computador, melhora relação professor- 
aluno, constituindo-se numa interação proveitosa tanto para o docente quanto para o discente. O aluno terá oportunidade de mostrar sua desenvoltura e aprendizado com o auxílio da máquina e o professor(a) poderá aprender com sua prática. Quanto aos aspectos negativos relativos aos fatores internos há o fato da própria composição instável do quadro docente; a unidade escolar tem um turn over de docentes não propício para processos adequados de capacitação, por isto a maioria dos docentes não tem oportunidade de se capacitarem, e com isso deixa de existir o estímulo coletivo da unidade escolar para o uso apropriado da sala de informática; a ausência de trabalhos integrativos promovidos por um profissional pedagógico específico que estabeleça mediação dos conteúdos escolares com os recursos tecnológicos na escola

Enfim, observando os resultados obtidos, decorrentes do projeto de ação, foi possível concluir que houve aproveitamentos, inclusive com um potencial significativo de transferência para a sala de aula. Um fato importante a considerar nesse estudo foi à relação pesquisadora-docentes, estabelecido numa metodologia simulada à coordenação de informática, auxiliando sempre que possível em suas inseguranças e acompanhando integralmente os projetos desde o início até o fim. Outro fato importante foi capacitação ocorrida dentro do ambiente de trabalho, na própria unidade escolar, trazendo resultados animadores para trabalho pedagógico.

As capacitações de informática educacional merecem uma reflexão mais aprimorada, colocando em perspectiva o significado dessa dimensão tecnológica. Os apontamentos introdutórios mostraram, através dos textos referidos, a complexidade desse assunto. As outras instâncias da sociedade, estatais e não estatais, integraram os sistemas de informática dentro de novas concepções de organização e de gestão. Grande parte do fluxo das informações e das operações dessas instâncias passa pelas redes de informação. Há, desse ponto de vista, necessidade de seus quadros de pessoal sempre se atualizarem e se integrarem nesses esquemas de informações. Sabemos, também, que nem sempre eles funcionam; a precariedade às vezes é uma norma. Vemos, sem sombra de dúvida, que a escola ainda não se integrou com esses sistemas de informações, no seu dia-a-dia. Por um lado, há muita insegurança, que poderá ser confundida com resistência, devido à existência de outros fatores desestimulantes da própria profissão. $\mathrm{O}$ fato das unidades escolares estarem com dificuldades na inserção da informatização em seu meio, pode ainda trazer muitas contribuições para o debate ético, moral e profissional a respeito dessa cultura emergente.

\section{Referências bibliográficas:}

BRASIL Ministério da Educação. Lei no 9.394, de 20 de dezembro de 1996. Brasília: MEC, 1996.

- Diretrizes Curriculares Nacionais para o Ensino

Fundamental. Brasília: MEC, 1998.

- Parâmetros Curriculares Nacionais: Ensino Fundamental

Brasília: MEC, 1999.

PROINFO: Informática e formação de professores. Brasília:

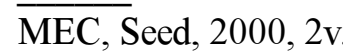

. PROINFO: Programa Nacional de Informática na Educação. Brasília: MEC, 2003. Disponível em: <http://www.mec.gov.br/seed/tvescola/ tvescola/proinfo.shtm>. Acesso em: 30 mar. 2003.

CAVACO, M.H. Oficio do professor: O tempo e as mudanças. In: NÓVOA, Antonio (Org.) Profissão professor. Porto: Porto, 1991, p.155-191.

GÓMEZ, A.P. O pensamento prático do professor: a formação do professor como profissional reflexivo. In: NOVOA, Antonio (Coord.). Os professores e sua formação. Lisboa: D.Quixote, 1992, p.93-114.

KENSKI, V. M A profissão do professor em um mundo em rede: exigências de hoje, tendências e construção do amanhã: professores, o futuro é hoje.

Revista Tecnologia Educacional, Rio de janeiro, v.26, n.143, p.65-69, out./ nov./dez. 1998.

. Em direção a uma ação docente mediada pelas tecnologias digitais. In: BARRETO, R.G. (Org.). Tecnologias educacionais e educação a distância: avaliando políticas e práticas. Rio de Janeiro: Quartet, 2001.

LIBÂNEO, J.C. Adeus professor. Adeus professora? Novas exigências educacionais e profissão docente. São Paulo: Cortez, 2001.

LÜDKE, M.; ANDRÉ, M.E.D.A. Pesquisa em educação: abordagens qualitativas. São Paulo: EPU, 1986. 
MARIN, A.J. Propondo um novo paradigma para formar professores a partir das dificuldades e necessidades históricas nessa área. In: REALLI, A.M.R.; MIZUKAMI, M.G. (Org.). Formação de professores: tendências atuais. São Carlos: EDUFSCar, p. 153-165,1996.

\section{MORAES, M. C. O paradigma educacional emergente. Campinas:} Papirus, 1997

. Informática educativa no Brasil: Uma história vivida, algumas lições aprendidas. Disponível em: $<$ http://www.edutec.net/Textos/Alia/MISC/ edmcandl.htm >. Acesso em: 30 mar. 2003.

MORAN, J.M.; BEHRENS, M.A.; MASETTO, M.T. Novas tecnologias e mediação pedagógica. São Paulo: Papirus, 2000.

PAPERT, Seymour. A máquina das crianças: repensando a escola na era da informática. Porto Alegre: Artes Médicas, 1994.

PERRENOUD, Philippe. Construir as competências desde a escola Porto Alegre: Artes Médicas, Sul, 1985.

Dez novas competências para ensinar. Porto Alegre: Artes Médicas Sul, 2000.

\section{ZEICHNER, K.M. A formação reflexiva de professores: idéias e} práticas. Lisboa: Educa, 1993, p.29-52.

. Tendências da pesquisa sobre formação de professores nos Estados Unidos. Revista Brasileira de Educação, São Paulo: ANPED, n.9, set./dez. 1998.

\section{Resumo:}

O objetivo principal desta pesquisa foi analisar a incorporação da cultura emergente na formação docente, ou seja, compreender como as novas tecnologias, recentemente difundidas nos meios educacionais, vêm sendo tratadas pelos processos de formação continuada e incluídas nas práticas pedagógicas.

$\mathrm{Na}$ delimitação do estudo, procuramos investigar as dificuldades dos professores com a utilização dos novos recursos tecnológicos, considerando-se os fatores internos e externos que possam estar inviabilizando o sucesso da inclusão digital no ambiente escolar da rede pública estadual. Assim, por meio da pesquisa qualitativa e avaliativa propiciada por um projeto de ação, buscamos entender as interferências que ocorrem na prática docente por meio de observações direcionadas ao desempenho dos professores na utilização dos recursos tecnológicos da sala de informática como instrumentos de desenvolvimento do ensino dos conteúdos escolares. Os resultados obtidos no projeto de ação originaram-se de declarações dos sujeitos e de observações estabelecidas nos módulos de capacitação e de aplicação dos planos de aulas.

Esses resultados convergem para os fatores desestimulantes como: excesso de movimentações dos docentes entre as escolas; ausência de pessoas credenciadas na própria escola capazes de coordenar as novas tecnologias educacionais e proporcionar segurança aos docentes; falta de capacitações no próprio ambiente escolar; carência de multiplicadores locais; ausência da previsão de tempo da preparação de aulas com os novos recursos tecnológicos na própria carga horária do professor e a inexistência de regulamentação na gestão administrativa que valorize o certificado da formação continuada. Enfim, as informações analisadas nessa pesquisa pelos aspectos positivos e negativos oferecem espaço para novas investigações dessa natureza.

\section{Palavras-chave:}

Formação Docente, Formação Continuada e Tecnologias Educacionais. 